\title{
Diagnosis of pupillary block glaucoma after removal of congenital cataracts with intraoperative ultrasound biomicroscopy: a case report
}

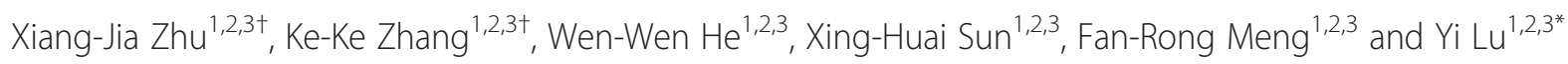

\begin{abstract}
Background: Aphakic glaucoma is a common complication after congenital cataract extraction, especially in those who have surgery during infancy. This case report describes a case of bilateral pupillary block glaucoma diagnosed with intraoperative ultrasound biomicroscopy (UBM) after removal of congenital cataract.

Case presentation: We present a case report of a 9-month-old infant with bilateral corneal enlargement and ocular hypertension after uneventful removal of congenital cataracts. Initial and follow-up examination findings were reviewed. The infant was suspected to have developmental glaucoma and schemed to have bilateral trabeculotomy until pupillary obstruction by vitreous herniation and angle closure with iris bombé were detected by intraoperative UBM. Anterior vitrectomy and goniosynechialysis were then performed as treatment.
\end{abstract}

Conclusion: Pupillary block glaucoma is a rare type of infantile aphakic glaucoma. Application of intraoperative UBM can assist in the differential diagnosis of aphakic glaucoma in infants.

Keywords: Pupillary block glaucoma, Aphakic glaucoma, Ultrasound biomicroscopy, Congenital cataract, Vitreous herniation

\section{Background}

Pediatric glaucoma [1-4] is a vision-threatening disease that constitutes a heterogeneous group of diseases including structural abnormalities of the aqueous outflow pathways (primary glaucoma) and abnormalities affecting other regions of the eye (secondary glaucoma). Early identification and treatment of glaucoma in children is vitally important to prevent vision loss. However, identifying the exact cause of ocular hypertension can sometimes be difficult especially in children who cannot cooperate with normal ophthalmic examinations. Pediatric glaucoma occuring in aphakic eyes after removal of congenital cataracts can be even confusing.

\footnotetext{
* Correspondence: luyieent@126.com

${ }^{\dagger}$ Equal contributors

'Department of Ophthalmology, Eye and Ear, Nose, and Throat Hospital, Fudan University, 83 Fenyang Road, Shanghai 200031, China

${ }^{2}$ Key Laboratory of Myopia, Ministry of Health, 83 Fenyang Road, Shanghai 200031, China

Full list of author information is available at the end of the article
}

Aphakic glaucoma is classified as secondary glaucoma and is a common complication after congenital cataract extraction, especially in those who have surgery during infancy $[5,6]$. It normally develops several years after cataract surgery, although it can also occur within weeks to months of surgery [7]. The mechanism for aphakic glaucoma is unclear, as the angle is usually open on gonioscopy. Acute or subacute angle closure with iris bombé is actually a rare form of aphakic glaucoma.

Our present case shows that intraoperative ultrasound biomicroscopy (UBM) could detect angle closure with iris bombé and pupillary obstruction by vitreous herniation in an aphakic infant and help the clinician make the appropriate surgical decision.

\section{Case presentation}

A 3-month-old female infant was admitted to our outpatient clinic on April 8, 2014 with parents' complaints of bilateral white cloudiness at the pupillary zone perceivedd 
1 month after birth. Preoperative ophthalmic examinations revealed complete bilateral lens opacification with clear corneas and anterior chambers. Since the infant did not cooperate with further examination of the posterior segment, we conducted B-scan ultrasonography of both eyes to screen abnormalities other than lens opacification, which showed negative results. Hence, she was diagnosed with bilateral congenital cataracts and underwent bilateral lensectomy, posterior capsulectomy and anterior vitrectomy under general anesthesia on April 9, 2014. Intraocular pressure (IOP) was OU $12 \mathrm{mmHg}$ with bilateral corneal diameter of $10 \mathrm{~mm}$ measured before the corneal incision was made. Intraoperative examination and postoperative B-scan ultrasonography showed negative results of posterior segment stuctures. Therefore, the patient was discharged after an uneventful postoperative course.

However, 6 months later, the infant was suspected to have bilateral developmental glaucoma with a mild enlargement of the corneal diameter, by a local hospital. She was then referred to our hospital again. The outpatient fundus examination revealed enlarged bilateral cupping with a cup-to-disc (C/D) ratio of $0.8 \mathrm{OU}$. IOP measured by schiotz tonometer was OD $19 \mathrm{mmHg}$ and OS $26 \mathrm{mmHg}$ on October 17, 2014, and OD $27 \mathrm{mmHg}$ and OS $19 \mathrm{mmHg}$ on October 21, 2014. The patient was then admitted to our inpatient department with the tentative diagnosis of bilateral developmental glaucoma. Ophthalmic examination showed IOP OD $52 \mathrm{mmHg}$ and OS $20 \mathrm{mmHg}$ (October 30, 2014; schiotz tonometer), mild opacification of the superior cornea in the right eye, clear cornea of the left eye, clear bilateral anterior chamber and visual axis zone. No retinal detachment was found with B-scan ultrasonography, and A scan showed axial lengths of OD $23.43 \mathrm{~mm}$ and OS $20.75 \mathrm{~mm}$. The patient was scheduled to receive bilateral trabeculotomy on October 31, 2014. Her intraoperative examination under general anesthesia showed IOP OD $35.8 \mathrm{mmHg}$ and OS $20.6 \mathrm{mmHg}$ (schiotz tonometer), superior opacification of the cornea in the right eye with a diameter of $11 \mathrm{~mm}$ (Fig. 1a) and a clear cornea in the left eye with a diameter of $10.5 \mathrm{~mm}$, clear bilateral anterior chambers, and increased $\mathrm{C} / \mathrm{D}$ ratio of OD 0.9-1.0 and OS 0.8-0.9. Gonioscopy examination showed almost overall angle closure and no detection of trabecular meshwork in both eyes, except that the superior section in the right eye was vague due to the cornea opacification. Intraoperative ultrasound biomicroscopy detected bilateral shallow anterior chambers of OD $1.75 \mathrm{~mm}$ and OS $1.95 \mathrm{~mm}$ in depth with the pupil diameter of OD $2.15 \mathrm{~mm}$ and OS $2.07 \mathrm{~mm}$, absence of the lens with a small amount of residual cortex out of the pupillary zone, and iris bombé with pupillary obstruction by vitreous herniation in both eyes (right eye in Fig. 1c-d and left eye in Fig. 1e-f). Middle-anterior positioned iris insertion, mildly extensive and anteriorly rotated ciliary process, and $360^{\circ}$ of peripheral anterior synechiae (PAS) and iris-trabecular meshwork contact were also observed in both eyes with UBM. Therefore, we altered the surgical plan to anterior vitrectomy and goniosynechialysis. The postoperative IOP was OU $16 \mathrm{mmHg}$. The infant was administered TobraDex Eye Drops (Alcon Laboratories, Inc., Fort Worth, TX, USA) TID OU and $1 \%$ pilocarpine (Bausch \& Lomb Freda, Shandong, China) BID OU. One week after the surgery, her IOP was OD $15 \mathrm{mmHg}$ and OS $16 \mathrm{mmHg}$. The whole changes of bilateral intraocular pressures in this case was shown Fig. 1b.

During the one-year follow-up in our medical centre after surgery, the infant showed no recurrent hypertension in the right eye. The intraocular pressure in the right eye maintained between 14 to $16 \mathrm{mmHg}$ using TonoPen XL tonometer (Medtronic Ophthalmics, MN, USA) after oral administration of chloralhydrate.

\section{Conclusions}

In this case, the aphakic infant presented bilateral ocular hypertension, corneal enlargement, and increased C/D ratio 6 months after congenital cataract removal. Though no solid evidence of glaucoma was observed in the previous cataract surgery, the possibility of developmental glaucoma was not ruled out. The surgical planning was bilateral trabeculotomy with intraoperative UBM examination, which later proved to be the turning point of our treatment. The patient was identified to have pupillary block associated with vitreous herniation which eventually developed into 360 angle closure secondary to PAS. Therefore, anterior vitrectomy and goniosynechialysis was applied instead of the original surgical plan, and the surgical outcome was satisfactory.

Acute angle closure glaucoma following pediatric cataract surgery is relatively uncommon. It has been reported that the pupillary block glaucoma usually occurs soon after surgery, but the onset can also be delayed by one year or more [8]. Our case showed mild but progressive bilateral corneal enlargement and ocular hypertension occured in six months after uneventful removal of congenital cataracts. Therefore, we suggested that special caution is required when IOP elevation or corneal enlargement is noted in aphakic young children.

Furthermore, before surgical intervention and intraoperative UBM examination, several causes of ocular hypertension should be considered: 1) compromised outflow of aqueous humor by combination of abnormal development of the anterior chamber angle [9], 2) The infants' susceptibility to inflammation induced by surgery [5], 3) the loss of lens support or vitreous factors that may obstruct the pupil, 4) infancy surgery $[6,10,11]$. 

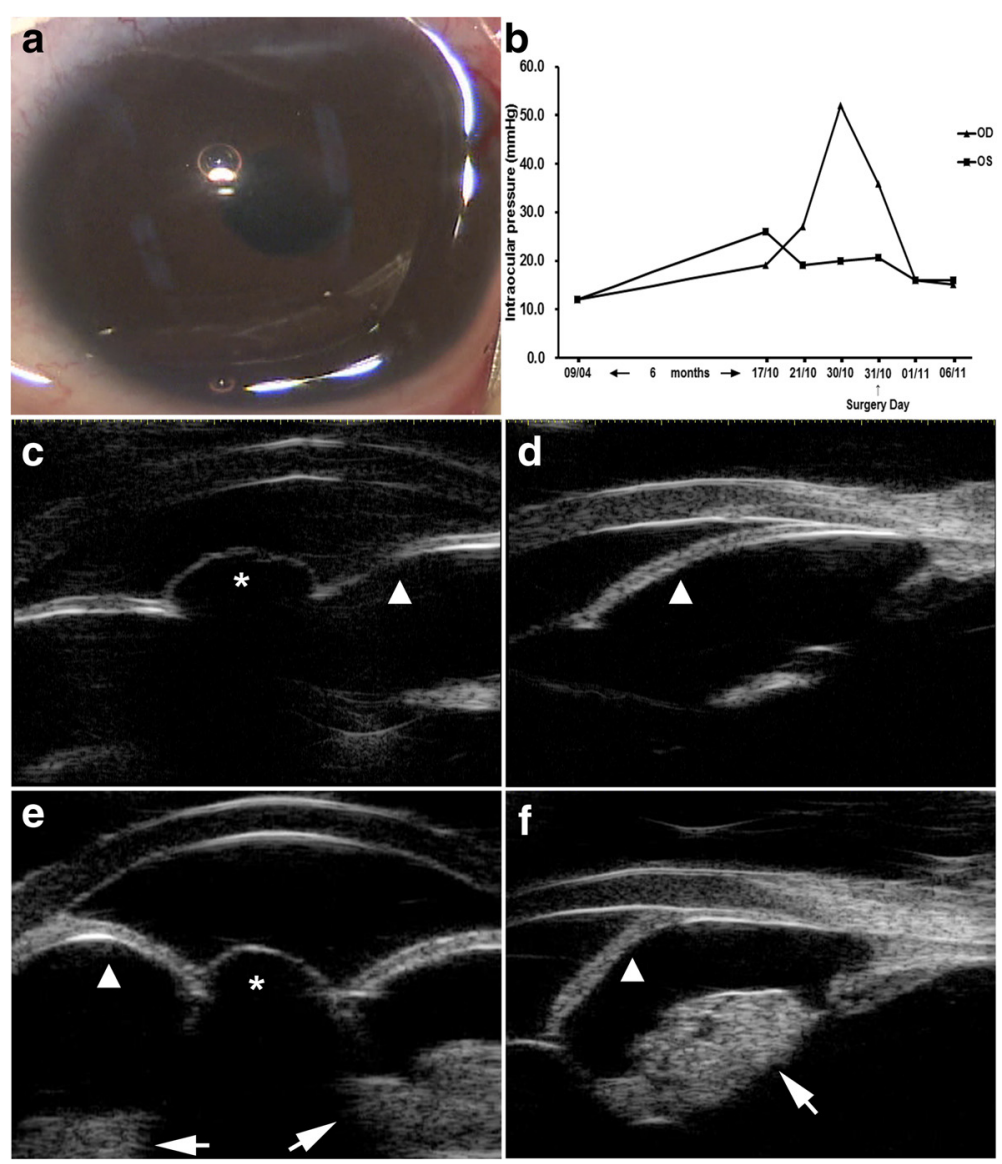

Fig. 1 a Surgical video screenshots of the anterior segment of the right eye of the patient. Aphakic pupillary block glaucoma by vitreous herniation was not easily identified even under surgical ophthalmoscope. b The changes of bilateral intraocular pressures from April 9, 2014 to November 6, 2014. c-f Intraoperative ultrasound biomicroscopy of the right ( $c$ and d) and the left eye (e and f) captured on October 31, 2014 (prior to anterior vitrectomy and goniosynechiolysis). Absence of lens with small amount of residual cortex was detected out of the pupillary zone (arrow) and iris bombé (arrow head) with pupillary obstruction by vitreous herniation (asterisk)

Intraoperative UBM finally confirmed the diagnosis as aphakic pupillary block glaucoma in this case. In many cases, this abnormal angle configuration should be apparent under slit lamp examination, however, such a diagnosis is difficult to make in young children who cannot cooperate for normal ophthalmic examination. Aphakic pupillary block glaucoma by vitreous herniation may not be easily identified even under surgical ophthalmoscope (Fig. 1a). A recent prospective investigational study suggested that UBM is a useful device to evaluate aphakic eyes before secondary IOL implantation through good evaluation of the anterior segment and detection of any structural changes in the anterior segment resulting from the remote cause of aphakia [12]. Therefore, our case further strengthened the importance of UBM in assessing the morphology of the anterior segment in this special population.

Both IOL implantation and peripheral iridotomy may influence and/or prevent vitreous-loss pupillary block. It is reported that phacoemulsification and IOL implantation is useful in IOP control for angle closure glaucoma after relief of pupillary block [13]. Also, peripheral iridotomy could prevent recurrence of acute primary angle closure and to reduce the risk of chronic rise in IOP [14]. Some previous studies also reported that peripheral iridectomy prevented the pseudophakic pupillary block glaucoma in children [15]. In our cases, the infant will be followed up and assessed in our medical centre for the possibility of IOL implantation after two years old.

Most of the prior studies on the vitreous effect on chamber angle in aphakic patients were based more on speculation rather than solid evidence $[5,10]$. In this case, with the assistance of UBM, we were able to identify those associated changes of the anterior segment. This technique greatly assisted in better understanding the cause of glaucoma in infants, especially for those with aphakic eyes after congenital cataract surgery. Intraoperative UBM examination is of substantial 
clinical value in differentiating the cause for elevated pressure in these patients.

\section{Consent}

As this is a single case report, our institutional review board at Ear, Nose, and Throat Hospital of Fudan University does not require approval. The ethical standards in the Declaration of Helsinki were adhered to. Written informed consent was obtained from the parents/legal guardians of the patient for publication of this case report and any accompanying images. A copy of the written consent is available for review by the Editor of this journal.

\section{Availability of data and materials}

All the data supporting our findings is contained within the manuscript.

\section{Abbreviations}

C/D: cup-to-disc; IOP: intraocular pressure; PAS: peripheral anterior synechiae; UBM: intraoperative ultrasound biomicroscopy.

\section{Competing interests}

The authors declare that they have no competing interests.

\section{Authors' contributions}

XJZ carried out the design of the study, data aquisition and critical revision of manuscript. KKZ carried out the data analysis and the manuscript drafting. WWH performed the statistical analysis and graph design. XHS participated in the funding securing of the study and provided the admin/technical/material support. FRM conceived of the study, and participated in its design and coordination and helped to revise the manuscript. YL performed the sugery, made critical revision of the manuscript, secured the admin/technical/material support, and made the final approval of the manuscript. All authors read and approved the final manuscript.

\section{Acknowledgements}

This research was funded by research grants from the National Natural Science Foundation of People's Republic of China (Grant No. 81270989 and 81470613), the National Health and Family Planning Commission of People's Republic of China (Grant No. 201302015), and the Cutting-Edge Technology Combined PR Project of Shanghai Shen Kang Hospital Development Centre (Grant No. SHDC12012104).

\section{Author details}

${ }^{1}$ Department of Ophthalmology, Eye and Ear, Nose, and Throat Hospital, Fudan University, 83 Fenyang Road, Shanghai 200031, China. ${ }^{2}$ Key Laboratory of Myopia, Ministry of Health, 83 Fenyang Road, Shanghai 200031, China. ${ }^{3}$ Key Laboratory of Visual Impairment and Restoration of Shanghai, Fudan University, 83 Fenyang Road, Shanghai 200031, China.

Received: 9 October 2015 Accepted: 11 May 2016

Published online: 17 May 2016

\section{References}

1. Mandal AK, Bhatia PG, Bhaskar A, Nutheti R. Long-term surgical and visual outcomes in Indian children with developmental glaucoma operated on within 6 months of birth. Ophthalmology. 2004;111:283-90.

2. Koc F, Kargi S, Biglan AW, Chu CT, Davis JS. The aetiology in paediatric aphakic glaucoma. Eye (Lond). 2006;20:1360-5.

3. Sahin A, Caca I, Cingu AK, Turkcu FM, Yuksel H, Sahin M, Cinar Y, Ari S. Secondary glaucoma after pediatric cataract surgery. Int J Ophthalmol. 2013;6:216-20.

4. Wagner RS. Glaucoma in children. Pediatr Clin North Am. 1993;40:855-67.

5. Chak M, Rahi JS, British Congenital Cataract Interest G. Incidence of and factors associated with glaucoma after surgery for congenital cataract: findings from the British Congenital Cataract Study. Ophthalmology. 2008; 115:1013-8 e2.
6. Sharma N, Pushker N, Dada T, Vajpayee RB, Dada VK. Complications of pediatric cataract surgery and intraocular lens implantation. J Cataract Refract Surg. 1999;25:1585-8.

7. Kang KD, Yim HB, Biglan AW. Comparison of delayed-onset glaucoma and early-onset glaucoma after infantile cataract surgery. Korean J Ophthalmol. 2006;20:41-6.

8. Bhola R, Keech RV, Olson RJ, Petersen DB. Long-term outcome of pediatric aphakic glaucoma. J AAPOS. 2006;10:243-8.

9. Wallace DK, Plager DA. Corneal diameter in childhood aphakic glaucoma. J Pediatr Ophthalmol Strabismus. 1996:33:230-4.

10. Asrani S, Freedman S, Hasselblad V, Buckley EG, Egbert J, Dahan E, Gimbel H, Johnson D, McClatchey S, Parks M, Plager D, Maselli E. Does primary intraocular lens implantation prevent "aphakic" glaucoma in children? J AAPOS. 2000;4:33-9.

11. Lundvall A, Zetterstrom C. Complications after early surgery for congenital cataracts. Acta Ophthalmol Scand. 1999;77:677-80.

12. Elfiky M, Saad $H$, Elseht $R$, Selima A. Role of ultrasound biomicroscopy in the planning for secondary implantation of intra ocular lens in aphakia. Int Ophthalmol 2015. [Epub ahead of print].

13. Kubota T, Toguri I, Onizuka N, Matsuura T. Phacoemulsification and intraocular lens implantation for angle closure glaucoma after the relief of pupillary block. Ophthalmologica. 2003;217(5):325-8.

14. Husain R, Gazzard G, Aung T, Chen Y, Padmanabhan V, Oen FT, Seah SK, Hoh ST. Initial management of acute primary angle closure: a randomized trial comparing phacoemulsification with laser peripheral iridotomy. Ophthalmology. 2012:119(11):2274-81.

15. Prasad S, Ram J, Sukhija J, Pandav SS, Gupta PC. Cataract surgery in infants with microphthalmos. Graefes Arch Clin Exp Ophthalmol. 2015;253(5):739-43.
Submit your next manuscript to BioMed Central and we will help you at every step:

- We accept pre-submission inquiries

- Our selector tool helps you to find the most relevant journal

- We provide round the clock customer support

- Convenient online submission

- Thorough peer review

- Inclusion in PubMed and all major indexing services

- Maximum visibility for your research

Submit your manuscript at www.biomedcentral.com/submit 